\title{
EPILEPSY AND ANXIETY
}

\author{
MARLY DE ALBUQUERQUE *, CARLOS JOSE REIS DE CAMPOS **
}

\begin{abstract}
SUMMARY - We have analyzed 155 subjects with STAI (State-Trait Anxiety Inventory): 75 epileptic patients and 80 normal subjects used as a control group. A higher trait-anxiety score (chronic anxiety) than that of controls was found for the epileptic group. For the epileptic group higher levels of the A-trait occurred in patients with EEG abnormalities with left temporal localization. We have also observed that the shorter the epilepsy lasts (less than two years), the higher the trait-anxiety levels. Convulsions and awareness loss during epileptic seizures do not modify state and trait-anxiety scores.
\end{abstract}

KEY WORDS: anxiety, epilepsy, anxiety-inventory, state-anxiety, trait-anxiety.

Epilepsia o ansiedade

RESUMO - Foram avaliados os níveis de ansiedade em 155 indivíduos pelo IDATE (Inventário de Ansiedade Traço-Estado). O grupo de estudo constou de 75 pacientes epilepticos matriculados no Setor de Investigação e Tratamento das Epilepsias da Disciplina de Neuroiogia da Escola Paulista de Medicina. O grupo controle foi constituído de 80 indivíduos normais. Foram observados maiores niveis de ansiedade crônica (Ansiedade-Traço) em epilépticos que em controles não epilépticos. Esses niveis foram tanto maiores quanto menor a duracão das epilepsias. Em toda a população epiléptica estudada, os níveis mais altos de ansiedade crônica ocorreram em pacientes com anormalidade do EEG de localização temporal esquerda. A perda ou não da consciência não interferiu nos níveis de ansiedade aguda (Ansiedade-Estado) ou crônica.

PALAVRAS-CHAVE: epilepsia, ansiedade, inventário de ansiedade traço-estado.

Many factors may contribute for the development of mental illness in epileptics: intractable epilepsy, cerebral lesion and even psychological, social and genetic factors. Anxiety can occur in a wide range of clinical states and it is a very common feature in epileptic patients. Anxiety can be considered a psychobiological state frequently associated to increased activity of the autonomic system. It is characterized by transitory physical and psychical feelings of tension, with expectation or fear that are not necessarily related to any impending danger situation. Neurosis is a cluster of symptoms related to fear, whose source is not recognized by out the patient. Anxiety can be observed in adults of both sexes. Its course may be acute or chronic. Anxiety has somatic and psychological components. These components may constitute appropriate reactions if there is an uncertain or threatening conditions. When anxiety is abnormal, it will occur in spite of these conditions or it will be an exaggerated reaction. The feeling of anxiety involves the integration of two elements: a background state of psychological arousal and a process of cognitive labeling to define the nature of the feeling emotion. Human anxiety has not been well

Escola Paulista de Medicina (FPM), Epilepsy Section: * M.D., M.Sc., Epilepsy Section EPM; ** M.D., M.Sc., Ph.D., Associated Professor of Clinical Neurology EPM, Chief of Epllepsy Section EPM. Master Thesis. Aceite: 20-janeiro-1993.

Dr. Carlos José Reis de Campos $\rightarrow$ Setor de Investigação e Tratamento das Epilepsias, Disciplina de Neurologia, Escola Paulista de Medicina - Rua Botucatu 740 - 04023-900 São Paulo SP - Brasil. 
understood and has been studied on an empirical basis 11,16. The discovery that anxiolytic (such as benzodiazepines and phenobarbital) and anxiogenic drugs (B-carbolines and GABA antagonists) make their pharmacological effects respectively by stimulating and inhibiting GABAergic transmission, suggests that the GABAergic system may be involved on the physiopathology of stress and anxiety 9 .

Epileptic seizures are associated to modifications in cerebral neurotransmitters 10. The inhibitory neurotransmitter GABA is found in larger quantities in mammalian brain 9 and it is responsible for $30.40 \%$ of CNS synapses 12,13. Some benzodiazepine effects are obtained by their interaction with GABA receptor 14. Chronic subictal activity leads to a kindling process in dopaminergic pathways, overactivity of which induce to the development of abnormal behavior ${ }^{30}$. Mattson et al.18, Bettz 1,3 and Temkim \& Davis 28 suggested that anxiety can increase the frequency of epileptic seizures, and Scott 25 related stress to a greater difficulty in seizure control. Zlutnick et al.31 and Ing 17 described the use of relaxation methods in order to decrease seizure frequency related to a reduction of the anxiety level. Different studies are still far from giving a conclusive answer to the following question: "what characterizes epileptic patients whose psychobiological conditions differs from day to day, whether they have had experienced epileptic seizures or not?".

The purpose of this work is to study epilepsy-related anxiety through the STAI, State-Trait Anxiety Inventory $4,27$.

\section{MATERIAL AND METHODS}

We have analyzed 75 out-patients from our Universitary Neurological Clinic with diagnosis of epilepsy (Epileptic Group) and 80 volunteers used as Control Group. All of them underwent STAI, State-Trait Ansiety Inventory 4,27.

The Epileptic Group was compozed of 75 patients with partial epilepsy and with single epileptic seizure type. The Control Group was composed of 80 volunteers, unskilled workers, who had no personal or familial history related to epilepsy and who had not been under antiepileptic or anxiolytic drug therapy during the evaluation period. Both groups were composed by subjects from both sexes, had a minimum of three years education in elementary school and had no major psychiatric illness. The patients did not undergo the STAI when they had a major convulsion in the previous 24 hours.

The diagnosis and classification of seizures and epilepsy syndromes were based on the International Classifications of Epileptic Seizures and Syndromes 6-8. The classification of seizures frequency was based on Pazzaglia et al.20. Every epileptic subject was submitted to at least one awake and one asleep electroencephalographic (EEG) examination. Subjects from the Control Group did not undergo EEG examination.

The STAI 4,27 consists of two different self-reporting series, organized for measuring two basic ideas: anxiety state (acute anxiety: A-state) and anxiety trait (chronic anxiety: A-trait). The A-state scores can vary in intensity and may change in time. The anxiety trait refers to a stable individual predisposition to develop an anxiety state.

The statistical significante was considered when $\mathrm{p}<0.05$ and the non-parametric tests: Mann Whitney, Kruskal-Wallis, Chi-square tests for $2 x N^{\prime}$ tables 15,26 were used for statistical analysis.

\section{RESULTS}

Of the 75 epileptic patients studied 42 were males and 33 females, the mean age (years) was 30.3 \pm 13.2 (range: 13-69). The Control Group was composed of 41 males and 39 females, the mean age (years) was $32.4 \pm 14.8$ (range: $13-60$ ).

The mean ages (years) of onset of epileptic seizures was $17.7 \pm-14.5$ (range: 1-61). The epileptic syndrome diagnosis was: $62.7 \%$ symptomatic partial epilepsy, $36.0 \%$ partial of undetermined cause and $0.3 \%$ idiopathic partial epilepsy. Familial history for epilepsy was found in $22.7 \%$ of patients.

The seizure types observed were: $65.3 \%$ simple partial, $33.4 \%$ complex partial and $1.3 \%$ sleep convulsion with normal EEG. Among patients with simple partial seizures, motor seizu- 
res were predominant $40.8 \%(20 / 49)$; convulsions occurred one time in $85.3 \%$ of the patients and $14.7 \%$ had only simple partial seizures. The epileptic seizures started when the patients were before 12 years of age in $37.3 \%$, between 12-18 years of age in $25.4 \%$ and over 18 in $37.3 \%$.

The epilepsy duration was less than 2 years in 12\%, between 2 and 5 years in $14.7 \%$ and over 5 years in $73.3 \%$. The mean period in which they have had seizures was 17.7 years. We observed a single epileptic seizure in $4 \%$ of the patients, one or less than one seizure a month in $28 \%$, more than one seizure a month in $45.3 \%$ and more than one seizure a week in $22.7 \%$.

Fifty six percent of the patients showed EEG abnormalities (spikes or siow waves). The localizations of BEG abnormalities were: right temporal focus in $36.2 \%$ (16/44), left temporal focus in $22.8 \%(10 / 44)$, bilateral temporal focus in $22.8 \%(10 / 44)$ and others in $18.1 \%(8 / 44)$.

The largest part of the patients $(71.9 \%)$ was on monopharmacy with Phenobarbital or Carbamazepine, and $28.1 \%$ in polipharmacy.

A statistically gignificant difference of the A-trait scores was showed when the Eptieptic Group results were compared with the Control Group (Table 1). As shown in Table 2, subjects with epilepsy onset of less than two yelars had a significantly higher A-trait score than any of the other epileptic patients. Also A-state scores were higher in epileptic patients with left temporal focus than in patients with EEG abnormalities with right or bilateral focus (Table 3). Conversely A-trait scores were not associated with lateralization of EEG abnormalities. Regarding social aspects for epileptic group, $65.3 \%$ were employed and $34.7 \%$ unemployed.

Table 1. Anxiety scores (STAI).

$$
\begin{array}{cc}
\text { Epileptic Group } & \text { Control Group } \\
\mathrm{N} 1=75 & \mathrm{~N} 2=80
\end{array}
$$

$\begin{array}{lccl}\begin{array}{l}\text { A. Acute anxiet: } \\ \text { (state scores) }\end{array} & \mathrm{X} 1=42.4 & \mathrm{X2}=41.4 & \mathrm{NS} \\ \begin{array}{l}\mathrm{B} \text {. Chronic anxiety } \\ \text { (trait scores) }\end{array} & \mathrm{X} 1=48.5 * & \mathrm{X2}=41.8 & \begin{array}{l}\mathrm{Z(U)}=4.52 * \\ (\mathrm{p}<0.05)\end{array}\end{array}$

$\mathrm{X} 1$ and $\mathrm{X2}$, mean value; NS, no significant statistical difference; Mann-Whitney test $\mathrm{Z}$ (crit.) $=1.96$.

Table 2. Epilepsy duration and chronic anxiety.

\begin{tabular}{lll}
\hline $\begin{array}{l}\text { Duration } \\
\text { (years) }\end{array}$ & $\begin{array}{l}\text { Chronic anxiety } \\
\text { (A-trait scores) }\end{array}$ \\
\hline \hline $01-2$ & $\mathrm{~N} 1=9$ & $\mathrm{X1}=56.89 *$ \\
$21-5$ & $\mathrm{~N} 2=11$ & $\mathrm{X} 2=46.82$ \\
$51-$ & $\mathrm{N3}=55$ & $\mathrm{X3}=47.36$
\end{tabular}

A-trait scores of STAI; N, subjects; $\mathrm{X}$, mean values.

Kruskal-Wallis test: $\mathrm{H}=8.85 * \mathrm{H}$ (crit.) $=-5.99 ; * \mathrm{X1}>\mathrm{X2}$ or $\mathrm{X3}(\mathrm{p}<0.05)$.

Table 3. A-state and EEG foci.

\begin{tabular}{lll}
\hline & & \multicolumn{1}{c}{$\begin{array}{c}\text { Acute anxiety } \\
\text { (A-state scores) }\end{array}$} \\
\hline Left temporal & $\mathrm{N} 1=10$ & $\mathbf{X} 1=50.80 *$ \\
Right temporal & $\mathrm{N} 2=16$ & $\mathbf{X} 2=39.94$ \\
Bilateral temporal & $\mathrm{N} 3=10$ & $\mathbf{X} 3=43.70$ \\
\hline
\end{tabular}

A-stiate scores of STAI; $N$, subjests; $X$, mean values.

Kruskal-Wallis test: $\mathrm{H}=5.9 * \mathrm{H}$ (crit.) $=5.9 ; * \mathrm{X} 1>\mathrm{X} 2$ or $\mathrm{X3} \quad(\mathrm{p}<0.05)$. 
A-state scores for epileptic patients were not associated with epilepsy duration, seizume frequency, age of onset, use of different antiepileptic drugs and employment situations. Similariy A-trait scores were not associated with age of onset, seizures frequency, different antiepileptic drugs and employement conditions.

\section{COMMENTS}

Higher A-trait scores have already been mentioned by Spielberger et al.27 and the only variable that these authors could relate to this finding was the age of onset of epileptic seizures. We did not observe A-trait or A-state scores to be related to the age of onset of epileptic seizures. Recently Bettz ${ }^{1-3}$ reported high A-state scores in epileptic patients, and suggested that this would be due to the fact that they became increasingly housebound and fearful of having attacks in public. However, in our study the A-state scores obtained from the Epileptic Group did not differ from those obtained from Control Group. This discrepancy may be explained for the acute anxiety is a transitory emotional state, very much inclined to variation, depending on situations related to environmental factors.

The Epileptic Group showed higher A-trait scores (mean score $=48.5$ ) than the Control Group (mean score $=41.8$ ), Table 1. The Epileptic Group also showed higher A-trait scores (mean score $=56.89$ ) when the epilepsy duration lasted less than two years (Table 2). These higher A-trait scores can be explained taking into consideration that these patients might have had little time to adapt themselves to the disease.

It has been suggested that the abnormal experiences associated with tem. poral lobe epilepsy, which increasingly became integrated into the person's psychic life, lead to the development of emotional disturbances 21. But, this explanation did not fit well with our findings, since the A-state scores that we observed were higher in patients with left temporal focus than in patients with right temporal focus or bilateral foci. This suggests that other factors may be associated with these emotional disturbances. On the other hand, Camfield et al.5 showed no association between anxiety scores and the localization of the EEG abnormalities on either left or right hemisphere. Nevertheless, the evaluation of focus laterality from ordinary surface EEG recordings is open to criticism, and a correlation between psychological disturbance and hemispheric lateralization has already been pointed out 22 . Even though these authors do not particularly refer to anxiety, they have found, like in our data, a higher frequency of psychopathologic disorders in epileptic patients with left temporal focus. Similarly to others 24 we have not observed different A-trait or A-state scores for different frequency of epileptic seizures.

Epilepsy diagnosis implies on fear of having seizures. It is important to observe that environmental circumstances do not necessarily cause emotions or stress: it is the personal interpretation of particular situations that leads to emotional responses.

Acute anxiety is very much inclined to variation on time and EEG recording may be made on other specific period. So, the paroxysmal discharge on EEG (left or right foci) may or may not be associated with high A-state scores. It is accepted that several mental disturbances are due mainly to the lasting antiepileptic therapy, seizure recurrence and its psychosocial consequences $1,23,29$. Low anxiety levels (acute or chronic anxiety) may be considered advantageous for a good performance during sustained stressful life situations. A-state scores (acute anxiety) are closely related to A-traits (chronic anxiety), i.e., persons with high A-trait scores are more inclined to have higher A-state scores 27 . Thus, we can usually expect greater resistance to stressful agents in individuals with low scores of A-trait 19 .

Epileptic patients suffer social stigmatization and a higher chronic anxiety could be partially explained because of their unemployement. However, among our subjects, we have not found any difference on chronic and acute anxiety in epileptic patients, whether they were working or not. Nevertheless we have not analyzed the influence of personal, educational, familiar and professional adjustments, which will be our aim for further studies. 
Chronic anxiety is more common in epileptic patients and, probably, the relationship between anxiety and epilepsy may be linked to the decrease of GABAergic transmission. On the other hand, the higher anxiety scores in epileptic patients might also be due to social stigmatization and discrimination. Emotions can interfere with epilepsy evolution and the epilepsies can change thoughts, emotions and beliefs, related to many episodic and unpredictable epileptic seizures (convulsions or psychic seizures) or even by their psychosocial repercussions.

Definitive conclusions are difficult to draw, since studies vary according to important parameters, including the amount and duration of medication intake, and the type, duration and severity of epileptic syndrome.

\section{HEFERENCES}

1. Bettz TA. Depression, anxiety and epilepsy. In Reynolds EH, Trimble MR: Epllepsy and psychiatry. Edinburgh: Churchill Livingstone, 1981, p 60-71.

2. Bettz TA. Psychiatry and epilepsy, part 1. In Laidlaw J, Richens A; A textbook of epilepsy. Edinburgh: Churchill Livingstone, 1982, p 227-270.

3. Bettz TA. Neuropsychiatry. In Laidlaw J, Richens A, Oxley J. A textbook of epilepsy. Edinburgh: Churchill Livingstone, 1988, p 358-385.

4. Biaggio AMB, Natalicio L. Manual para o inventário de ansiedade traço-estado IDATE. São Paulo: Centro Editor de Psicologia Aplicada, 1979.

5. Camfield PR, Gates R, Ronen G, Camfield C, Ferguson A, MacDonald GW. Comparison of cognitive ability, personality profile and school success in epileptic children with pure versus right left temporal lobe EEG foci. Ann Neurol 1984, 15:122-126.

6. Comission on Classification and Terminology of the International League Against Epilepsy. Proposal for classification of epilepsies and epileptic syndromes. Epilepsia 1985, 26:268-278.

7. Commission on Classification and Terminology of the International League Against Epilepsy. Proposal for revised classification of epilepsies and epileptic syndromes. Epilepsia 1989, 30:389-399.

8. Commission on Classification and Terminology of the International League Against Epilepsy. Proposal for revised clinical and electroencephalographic classification of seizures. Epilepsia 1989, 22:489-501.

9. Corda MG, Biggio G. Stress and GABAergic transmission: biochemical and behavioral studies. In Biggio G, Costa E: GABAergic transmission and anxiety. New York: Raven Press, 1986.

10. Fariello RG. Biochemical approaches to seizures mechanisms: the GABA and glutamate systems. In Poster RJ, Morselli PL. London: Butterworths, 1985, p 1-19.

11. Gardner CR. Recent developments in 5HT-related pharmacology of animal models of anxiety. Pharmacol Biochem Behav 1986, 24:1479-1485.

12. Haefely W. Antagonists of benzodiazepines: functional aspects. Adv Biochem Psychopharmacol 1983, 38:73-93.

13. Haefely W. Benzodiazepine interactions with GABA receptors. Neurosc Lett 1984, 47: 201-206.

14. Haefely W, Polc P. Electrophysio'ogical studies on the interaction of anxiolytic drugs with GABAergic mechanisms. In Enna SJ, Yamamura HI, Mallick JB. Anxiolytics: neurochemical, behavioral and clinical perspective. New York: Raven Press, 1983.

15. Hollander M, Wolfe DA. Nonparametric statistical methods. New York: John Wiley \& Sons, 1973.

16. Humble M. Aetiology and mechanisms of anxiety disorders. Acta Psychiat Scand 1987, $76: 15-30$.

17. Ing LP. The use of relaxation training and a conditioned stimulus in the elimination of epileptic seizures in a child: a case study. $J$ Behav Ther Exp Psychiat 1976, 7:39-42.

18. Mattson RH, Heninger GR, Gallagher BB, Glaser GH. Psychophysiologic precipitates of seizures in epileptics. Neurology 1970, 20:407-411.

19. Milgran NA, Zucker M. Congruent stress-preventing factors and anxiety in a long-term stress situation. J Human Stress 1985, 11:184-189.

20. Pazzaglia P, D'Alessandro R, Lozito A, Lugaresi E. Classification of partial epilepsies according to the symptomatology of seizures: practical value and prognosis implications. Epilepsia 1982, 23:343-350.

21. Pond DA. The schizophrenia-like psychoses of epilepsy: discussion. Proc $R$ Soc Med $1962,55: 311-323$.

22. Pritchard PB, Lombroso CT, McIntyre M. Psychological complications of temporal lobe epilepsy. Neurology 1980, 30:227-232. 
23. Reynolds EH. Chronic antiepileptic toxicity: a review. Epilepsia 1975, 16:319-352.

24. Robertson Mar, Trimble MR, Townsend HRA. Phenomenology of depression in epilepsy. Epilepsia 1987, 28:364-372.

25. Scott DF. Psychiatric aspects of epilepsy: review article. Br J Psychiat 1978, 132:417-430.

26. Siegel $\mathbf{S}$. Nonparametric statistics for the behavioral sciences. New York: McGraw-Hill, 1956.

27. Spielberger CD, Gorsuch RL, Luchene RE. Manual for the state-trait anxiety inventory (self-evaluation questionnaire). Palo Alto: Consulting Psychologists Press, 1970.

28. Temkin NR, Davis GR. Stress as a risk for seizures among tadults with epilepsy. Epilepsia 1984, 25:450-456.

29. Trimble MR. Anticonvulsant drugs: mood and cognitive funcion. In Epilepsy, behavior and cognitive function. Chichester: John Wiley \& Sons, 1988, p 135-143.

30. Trimble MR. Psychiatric and psychological aspects of epilepsy. In Porter RJ, Morselli PL: The epilepsies. London: Butterworths, 1985, p 322-355.

31. Zlutinick S, Mayville W, Moffat S. Behavioral control of seizure disorders: the interruption of chained behavior. In Katz RC, Slutinick S: Behavior therapy and care. New York: Pergamon Press, 1975, p 317-336. 